\title{
Applicability of Simplified Simulation Models for Perforation-Mediated Modified Atmosphere Packaging of Fresh Produce
}

\author{
Min-Ji Kwon, Yun Hee Jo, Duck Soon An, and Dong Sun Lee \\ Department of Food Science and Biotechnology, Kyungnam University, 449 Woryeong-dong, Masanhappo-gu, \\ Changwon 631-701, Republic of Korea \\ Correspondence should be addressed to Dong Sun Lee; dongsun@kyungnam.ac.kr
}

Received 6 May 2013; Accepted 28 June 2013

Academic Editor: Vanee Chonhenchob

Copyright (C) 2013 Min-Ji Kwon et al. This is an open access article distributed under the Creative Commons Attribution License, which permits unrestricted use, distribution, and reproduction in any medium, provided the original work is properly cited.

\begin{abstract}
The comprehensive mass balances of differential equations involving gas diffusion and hydraulic convection through package perforation, gas permeation through polymeric film, and produce respiration have commonly been used to predict the atmosphere of perforated fresh produce packages. However, the predictions often suffer from instability, and to circumvent this problem, a simplified diffusion model that omits the convective gas transfer and empirical models based on experimental mass transfer data have been developed and investigated previously by several researchers. This study investigated the potential and limitations of the simplified diffusion model and two empirical models for predicting the atmosphere in perforated produce packages. The simplified diffusion model satisfactorily estimated the atmosphere inside the perforated packages of fresh produce under the aerobic conditions examined. Published empirical models of the mass transfer coefficients of the perforation seem to be valid only for the measured conditions and thus should be used carefully for that specific purpose.
\end{abstract}

\section{Introduction}

Perforation or diffusion channel has been made or attached to plastic packages of fresh produce to maintain the desired modified atmosphere (MA) for a variety of commodities and storage conditions. The perforation or diffusion channel can partially overcome the gas permeability limitations of the available plastic packaging layers. Plastic packaging materials have narrow ranges of $\mathrm{CO}_{2}$ and $\mathrm{O}_{2}$ permeabilities, with the relative ratio of the former to the latter in the range of 3-7, which is suitable for creating an MA of low-tohigh $\mathrm{O}_{2}$ concentration and low $\mathrm{CO}_{2}$ concentration $[1,2]$. In some cases, the gas permeabilities of the plastic packages are not high enough to balance the high respiration of certain commodities, thus creating an anaerobic atmosphere inside the package. The addition of perforations to the package can increase the gas permeation and modify the relative ratio of $\mathrm{CO}_{2}$ permeation to $\mathrm{O}_{2}$ permeation, allowing an MA with low $\mathrm{O}_{2}$ and high $\mathrm{CO}_{2}$ concentrations $[3,4]$.

The perforated packages for a desired MA can be designed to balance the produce respiration and the package gas permeation by adjusting the number, diameter, and length of the perforations. In order to expedite the design process, mathematical models for estimating the package atmosphere have been developed and proposed by several researchers [5]. Rodriguez-Aguilera and Oliveira [6] have reviewed the published mathematical models on the mass transfer through the micro- or macroperforated polymeric films. There are variations among the models in their approaches, assumptions, and simplifications for gas transfer through the perforations: some are based on the physical principles of mass transfer, and others are based on empirical regression of experimental data on the changes in the gas composition inside the perforated packages. The typical comprehensive model based on physical principles addresses gas diffusion and convective hydraulic gas flow through the perforations, gas permeation through the polymeric layer, and produce respiration [7-10], but it often has the drawback of instability in the solution [11]. A simplified version that omits the convective gas transfer is often used for the ease of building the system equations and for ensuring the stability of the 
solution of the differential equations [12-14]. The empirical models present lumped mass transfer coefficients of $\mathrm{O}_{2}$ and $\mathrm{CO}_{2}$ gases as a function of perforation diameter, length, and/or temperature $[5,15,16]$. To satisfy the specific demands for usage and application conditions, many sophisticated mathematical models that take into account factors such as the porosity of the produce, $\mathrm{CO}_{2}$ solubility of the produce, gas concentration distribution in the container, transpiration and water vapor balance, and external air velocity have been proposed [17-19].

Although any model has specific targets for application, with associated advantages and disadvantages, the models should be evaluated by their prediction accuracy and convenience. By comparing the mathematical models based on prediction outcomes for different commodities and package configurations, the models can be used to successfully design perforated produce packages.

Therefore, this study aims to evaluate the different mathematical models of perforated fresh produce packages with respect to their prediction accuracy and practical usefulness. The results of the simulations of each model were compared to the literature data first and then the effects of omitting the convective gas transfer were examined for a model package system of two commodities.

\section{Materials and Methods}

2.1. Simulation Models for Package Atmosphere Changes. Four different mathematical models used for estimating the atmosphere of perforated fresh produce packages were compared. The first model examined was the comprehensive theoretical mass balance model, which includes diffusive gas fluxes through the plastic wall and the perforations, convective hydraulic gas flow through the perforation, and respiration rates of $\mathrm{O}_{2}$ consumption and $\mathrm{CO}_{2}$ production [7-10]:

$$
\begin{aligned}
\frac{d n_{\mathrm{O}_{2}}}{d t}= & \frac{N D_{\mathrm{O}_{2}} A\left(0.21 p_{a}-p_{\mathrm{O}_{2}}\right)}{L+\delta}\left(\frac{1}{R T}\right) \\
& +\frac{\bar{P}_{\mathrm{O}_{2}} S\left(0.21 p_{a}-p_{\mathrm{O}_{2}}\right)}{B} \\
& -W R_{\mathrm{O}_{2}}+\frac{N \pi d^{4}\left(p_{a}-p_{t}\right) p_{p, \mathrm{O}_{2}}}{128 \mu L R T}, \\
\frac{d n_{\mathrm{CO}_{2}}=}{d t}= & \frac{N D_{\mathrm{CO}_{2}} A\left(0.00-p_{\mathrm{CO}_{2}}\right)}{L+\delta}\left(\frac{1}{R T}\right) \\
& +\frac{\bar{P}_{\mathrm{CO}_{2}} S\left(0.00-p_{\mathrm{CO}_{2}}\right)}{B} \\
& +W R_{\mathrm{CO}_{2}}+\frac{N \pi d^{4}\left(p_{a}-p_{t}\right) p_{p, \mathrm{CO}_{2}}}{128 \mu L R T}, \\
\frac{d n_{\mathrm{N}_{2}}}{d t}= & \frac{N D_{\mathrm{N}_{2}} A\left(0.78 p_{a}-p_{\mathrm{N}_{2}}\right)}{L+\delta}\left(\frac{1}{R T}\right)
\end{aligned}
$$

$$
\begin{array}{r}
+\frac{\bar{P}_{\mathrm{N}_{2}} S\left(0.78 p_{a}-p_{\mathrm{N}_{2}}\right)}{B} \\
+\frac{N \pi d^{4}\left(p_{a}-p_{t}\right) p_{p, \mathrm{~N}_{2}}}{128 \mu L R T},
\end{array}
$$

where $n_{\mathrm{O}_{2}}, n_{\mathrm{CO}_{2}}$, and $n_{\mathrm{N}_{2}}$ are the respective mole numbers in the container of $\mathrm{O}_{2}, \mathrm{CO}_{2}$, and $\mathrm{N}_{2}$ gases at time $t(\mathrm{~h}) ; D_{\mathrm{O}_{2}}$, $D_{\mathrm{CO}_{2}}$, and $D_{\mathrm{N}_{2}}$ are the respective diffusivity of $\mathrm{O}_{2}, \mathrm{CO}_{2}$, and $\mathrm{N}_{2}$ gases in air $\left(\mathrm{m}^{2} \mathrm{~h}^{-1}\right) ; N$ is the number of perforations of length $L(\mathrm{~m})$, diameter $d(\mathrm{~m})$, and cross-sectional area $A$ $\left(\mathrm{m}^{2}\right) ; \delta$ is a correction term for gas diffusion resistance in the perforations (1.1d); $B$ and $S$ are the thickness $(\mathrm{mm})$ and surface area $\left(\mathrm{m}^{2}\right)$ of the plastic layer, respectively; $\bar{P}_{\mathrm{O}_{2}}, \bar{P}_{\mathrm{CO}_{2}}$, and $\bar{P}_{\mathrm{N}_{2}}$ are the respective gas permeabilities of the plastic layer against $\mathrm{O}_{2}, \mathrm{CO}_{2}$, and $\mathrm{N}_{2}\left(\mathrm{~mol} \mathrm{~mm} \mathrm{~m} \mathrm{~m}^{-2} \mathrm{~Pa}^{-1}\right)$; $p_{t}$ is the total pressure of the container $(\mathrm{Pa}) ; R$ is the gas constant $\left(8.314 \mathrm{~J} \mathrm{~K}^{-1} \mathrm{~mol}^{-1}\right) ; T$ is the temperature $(\mathrm{K}) ; \mu$ is the viscosity of air $\left(\mathrm{kg} \mathrm{m}^{-1} \mathrm{~h}^{-1}\right) ; W$ is the produce weight $(\mathrm{kg}) ; R_{\mathrm{O}_{2}}$ is the respiration rate of $\mathrm{O}_{2}$ consumption $\left(\mathrm{mol} \mathrm{kg}^{-1} \mathrm{~h}^{-1}\right) ; R_{\mathrm{CO}_{2}}$ is the respiration rate of $\mathrm{CO}_{2}$ production $\left(\mathrm{mol} \mathrm{kg}^{-1} \mathrm{~h}^{-1}\right)$; and $p_{p, \mathrm{O}_{2}}, p_{p, \mathrm{CO}_{2}}$, and $p_{p, \mathrm{~N}_{2}}$ are the respective partial pressures of $\mathrm{O}_{2}, \mathrm{CO}_{2}$, and $\mathrm{N}_{2}$ in the ambient air when $p_{t}$ is less than normal atmospheric pressure $\left(p_{a}, 1.013 \times 10^{5} \mathrm{~Pa}\right)$ and are the partial pressures in the container when $p_{t} \geq p_{a}$. The first and last terms on the right side of (1)-(3) represent gas diffusion based on Fick's law and convective hydraulic gas transfer through the perforations based on the Poiseuille equation, respectively. The second term in (1)-(3) describes the diffusive gas permeation through the plastic layer, and the third term in (1) and (2) indicates the respiration activity. The gas transfer model of (1)-(3) has been termed as Fick's law and Poiseuille approach by Rodriguez-Aguilera and Oliveira [6].

Although (1)-(3) (hereafter referred to as the comprehensive model) are comprehensive in including the major contributions to the mass balance, instability problems may arise for certain perforation conditions; these problems are caused when the value for the convectional terms is much larger than for the other terms under certain pressure differential conditions [9]. Simplifying (1)-(3) by removing the convection terms may have the potential to resolve the stiffness and instability problems only with a slight sacrifice in the accuracy $[17,20]$. Thus, the simplified versions ((4)(6), hereafter referred to as the simplified diffusion model) were examined in the simulation:

$$
\begin{aligned}
\frac{d n_{\mathrm{O}_{2}}}{d t}= & \frac{N D_{\mathrm{O}_{2}} A\left(0.21 p_{a}-p_{\mathrm{O}_{2}}\right)}{L+\delta}\left(\frac{1}{R T}\right) \\
& +\frac{\bar{P}_{\mathrm{O}_{2}} S\left(0.21 p_{a}-p_{\mathrm{O}_{2}}\right)}{B}-W R_{\mathrm{O}_{2}}, \\
\frac{d n_{\mathrm{CO}_{2}}}{d t}= & \frac{N D_{\mathrm{CO}_{2}} A\left(0.00-p_{\mathrm{CO}_{2}}\right)}{L+\delta}\left(\frac{1}{R T}\right) \\
& +\frac{\bar{P}_{\mathrm{CO}_{2}} S\left(0.00-p_{\mathrm{CO}_{2}}\right)}{B}+W R_{\mathrm{CO}_{2}},
\end{aligned}
$$




$$
\begin{gathered}
\frac{d n_{\mathrm{N}_{2}}}{d t}=\frac{N D_{\mathrm{N}_{2}} A\left(0.78 p_{a}-p_{\mathrm{N}_{2}}\right)}{L+\delta}\left(\frac{1}{R T}\right) \\
+\frac{\bar{P}_{\mathrm{N}_{2}} S\left(0.78 p_{a}-p_{\mathrm{N}_{2}}\right)}{B} .
\end{gathered}
$$

Because the nitrogen change is usually very small for common situations and the molecules of most interest in the package atmosphere are $\mathrm{O}_{2}$ and $\mathrm{CO}_{2},(6)$, which is independent from (4) and (5), may be omitted in the solution. This simplified diffusion model has been covered in Fick's law approach by Rodriguez-Aguilera and Oliveira [6].

Two empirical models correlating the gas exchange flow of the perforation to its physical dimensions were also tested for their ability to predict the atmosphere of the perforated packages. These models, which were built using experimental gas transfer data for various physical perforation dimensions, lump the first and last terms in (1) and (2) into a parameter ( $K_{\mathrm{O}_{2}}$ for (1) and $K_{\mathrm{CO}_{2}}$ for (2)) called the mass transfer coefficient or gas transmission rate $\left(\mathrm{m}^{3} \mathrm{~h}^{-1}\right)$. Nitrogen transfer across the package layer is neglected. Hence, the empirical models can be described as follows:

$$
\begin{aligned}
\frac{d n_{\mathrm{O}_{2}}}{d t}= & \left(\frac{N K_{\mathrm{O}_{2}}\left(0.21 p_{a}-p_{\mathrm{O}_{2}}\right)}{R T}\right) \\
& +\frac{\bar{P}_{\mathrm{O}_{2}} S\left(0.21 p_{a}-p_{\mathrm{O}_{2}}\right)}{B}-W R_{\mathrm{O}_{2}}, \\
\frac{d n_{\mathrm{CO}_{2}}}{d t}= & \left(\frac{N K_{\mathrm{CO}_{2}}\left(0.00-p_{\mathrm{CO}_{2}}\right)}{R T}\right) \\
& +\frac{\bar{P}_{\mathrm{CO}_{2}} S\left(0.00-p_{\mathrm{CO}_{2}}\right)}{B}+W R_{\mathrm{CO}_{2}} .
\end{aligned}
$$

The model of Fonseca et al. [16] (hereafter referred to as Fonseca's empirical model) provides the $\mathrm{O}_{2}$ and $\mathrm{CO}_{2}$ mass transfer coefficients $\left(K_{\mathrm{O}_{2}}\right.$ and $\left.K_{\mathrm{CO}_{2}}\right)$ in the simplified functional forms of the perforation dimensions:

$$
\begin{gathered}
K_{\mathrm{O}_{2}}=2.31 \times 10^{-2} d^{1.45} L^{-0.598}, \\
K_{\mathrm{CO}_{2}}=0.81 K_{\mathrm{O}_{2}} .
\end{gathered}
$$

The model of Emond et al. [15] (hereafter referred to as Emond's empirical model) relates the $\mathrm{O}_{2}$ and $\mathrm{CO}_{2}$ mass transfer coefficients to the perforation dimensions and temperature using polynomial functions:

$$
\begin{aligned}
K_{\mathrm{O}_{2}}= & -4.73360 \times 10^{-3}+0.15645 L \\
& +1.89890 \times 10^{-5} \mathrm{~T}+3.60860 \times 10^{4} d^{4} \\
& +1.86600 L^{2}-2.58396 \times 10^{2} d^{2} L \\
& -7.0900 \times 10^{-4} L T,
\end{aligned}
$$

$$
\begin{aligned}
K_{\mathrm{CO}_{2}}= & -5.22401 \times 10^{-2}+0.13294 L+3.54100 \\
& \times 10^{-4} T+2.98700 L^{2}-5.92740 \times 10^{-7} T^{2} \\
& -2.74497 \times 10^{2} d^{2} L+2.11822 \\
& \times 10^{-2} d^{2} T-6.72840 \times 10^{-4} L T .
\end{aligned}
$$

The respiration rates $\left(R_{\mathrm{O}_{2}}\right.$ and $\left.R_{\mathrm{CO}_{2}}\right)$ in the $\mathrm{O}_{2}$ and $\mathrm{CO}_{2}$ mass balance equations ((1), (2), (4), (5), and (7)) may be supplied using any appropriate data or model. An enzyme kinetics-based model describing the respiration as a function of $\mathrm{O}_{2}$ and $\mathrm{CO}_{2}$ concentrations can be conveniently used in the simulation $[24,25]$ :

$$
R_{\mathrm{O}_{2}} \text { or } R_{\mathrm{CO}_{2}}=\frac{V_{m} p_{\mathrm{O}_{2}}}{K_{m}+\left(1+p_{\mathrm{CO}_{2}} / K_{i}\right) p_{\mathrm{O}_{2}}},
$$

where $V_{m}, K_{m}$, and $K_{i}$ are the parameters.

The solution of the equations obtained for the moles of gas in the container for any time $t$ can be converted using the ideal gas law to partial pressures of $\mathrm{O}_{2}, \mathrm{CO}_{2}$, and $\mathrm{N}_{2}\left(p_{\mathrm{O}_{2}}\right.$, $p_{\mathrm{CO}_{2}}$, and $p_{\mathrm{N}_{2}}$ ) or to volumetric percentages under normal atmosphere. The simultaneous differential equations were solved in MatLab code by Gear's method under different control regimes.

2.2. Comparison of the Simulation Results and the Package Atmosphere Data from the Literature. Experimental data for perforated produce packages in the literature that contained all the information on package dimensions, gas permeability, perforation conditions, storage temperature, and produce respiration were collected. Simulations using the four models examined were performed for each specific package and storage condition. The results of the simulations were compared to the literature data for the experimental package atmosphere.

2.3. Comparison of the Mechanistic Models for Different Perforation Conditions Using a Model Package System. The solution outcomes of two mechanistic models, the comprehensive model and the simplified diffusion model, were investigated for a model package with a variety of perforation dimensions. The model package for the study, a plastic box made of $2 \mathrm{~mm}$ thick polypropylene with dimensions of $0.32 \times 0.23 \times$ $0.18 \mathrm{~m}$, had a perforation, and it could hold $0.35 \mathrm{~kg}$ of spinach or $0.9 \mathrm{~kg}$ of king oyster mushrooms; storage was at $10^{\circ} \mathrm{C}$ [11]. The permeability values of the polypropylene shell were taken to be $5.71 \times 10^{-10}, 1.63 \times 10^{-9}$, and $1.14 \times$ $10^{-10} \mathrm{~mol} \mathrm{~mm} \mathrm{~m}^{-2} \mathrm{~h}^{-1} \mathrm{~Pa}^{-1}$ for $\mathrm{O}_{2}, \mathrm{CO}_{2}$, and $\mathrm{N}_{2}$ at $10^{\circ} \mathrm{C}[1]$. The respiration kinetic data for spinach and king oyster mushrooms at the same temperature were adopted from Jo et al. [11]: $V_{m}=1.911 \times 10^{-3} \mathrm{~mol} \mathrm{~kg}^{-1} \mathrm{~h}^{-1}, K_{m}=3.58 \mathrm{kPa}$, and $K_{i}=22.4 \mathrm{kPa}$ for the $R_{\mathrm{O}_{2}}$ of spinach; $V_{m}=1.516 \times$ $10^{-3} \mathrm{~mol} \mathrm{~kg}^{-1} \mathrm{~h}^{-1}, K_{m}=3.32 \mathrm{kPa}$, and $K_{i}=17.2 \mathrm{kPa}$ for the $R_{\mathrm{CO}_{2}}$ of spinach; $V_{m}=5.717 \times 10^{-3} \mathrm{~mol} \mathrm{~kg}^{-1} \mathrm{~h}^{-1}, K_{m}=$ $5.92 \mathrm{kPa}$, and $K_{i}=140.6 \mathrm{kPa}$ for the $R_{\mathrm{O}_{2}}$ of king oyster mushrooms; and $V_{m}=2.386 \times 10^{-3} \mathrm{~mol} \mathrm{~kg}^{-1} \mathrm{~h}^{-1}, K_{m}=0.03 \mathrm{kPa}$, and $K_{i}=85.0 \mathrm{kPa}$ for the $R_{\mathrm{CO}_{2}}$ of king oyster mushrooms. The package atmosphere was simulated for the perforation diameters and lengths of interest by using the comprehensive 


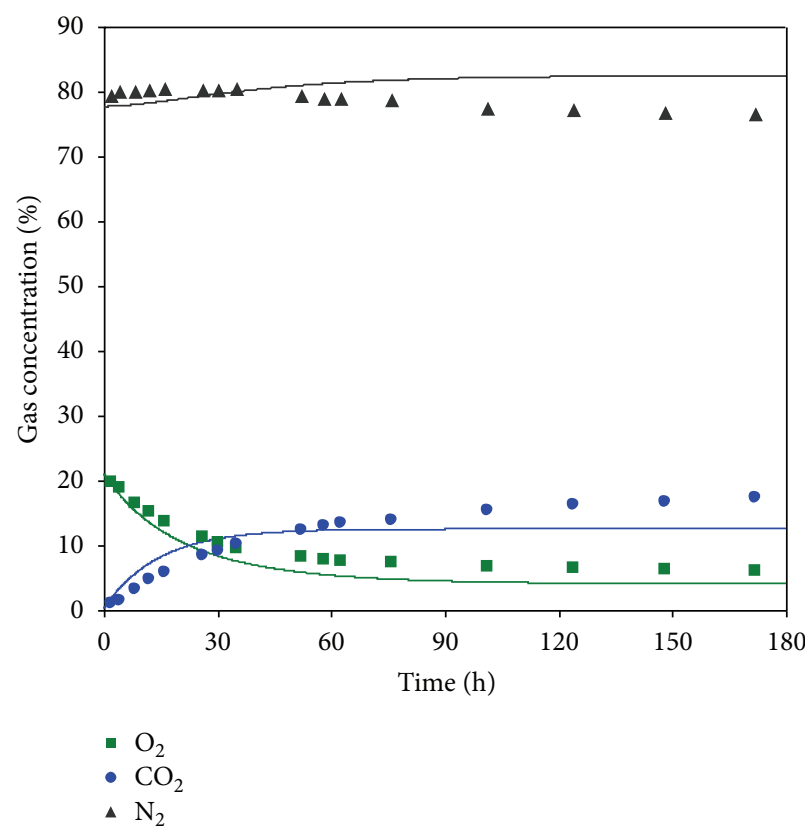

(a)

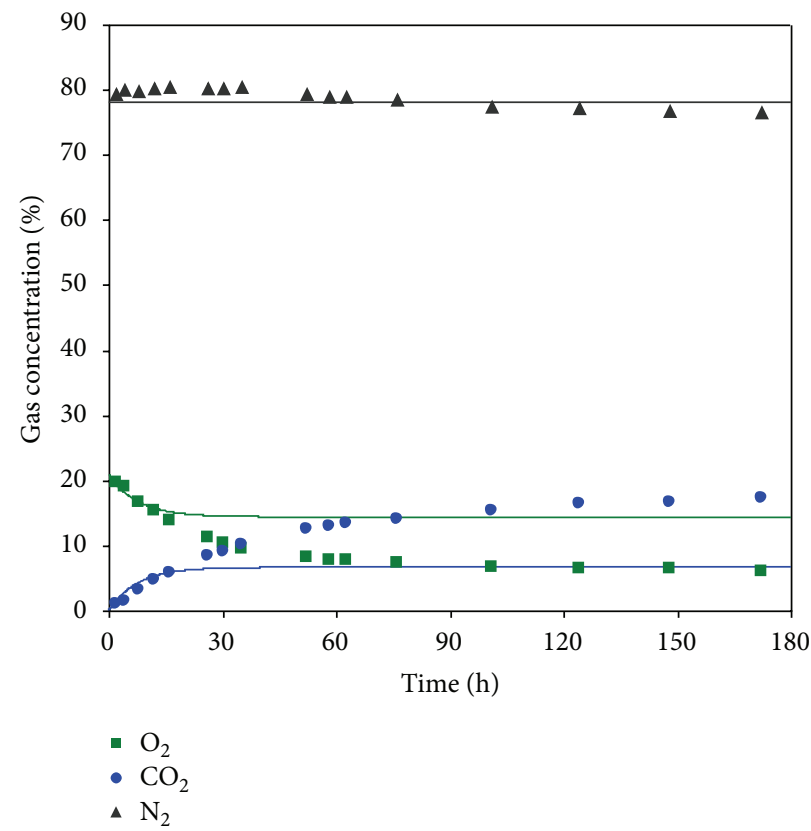

(c)

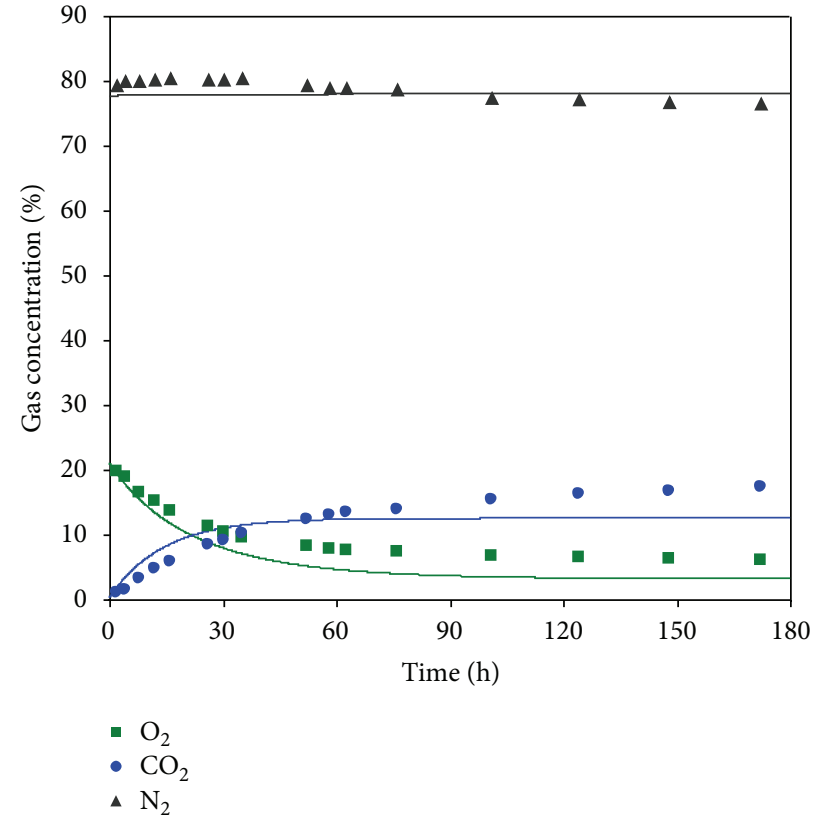

(b)

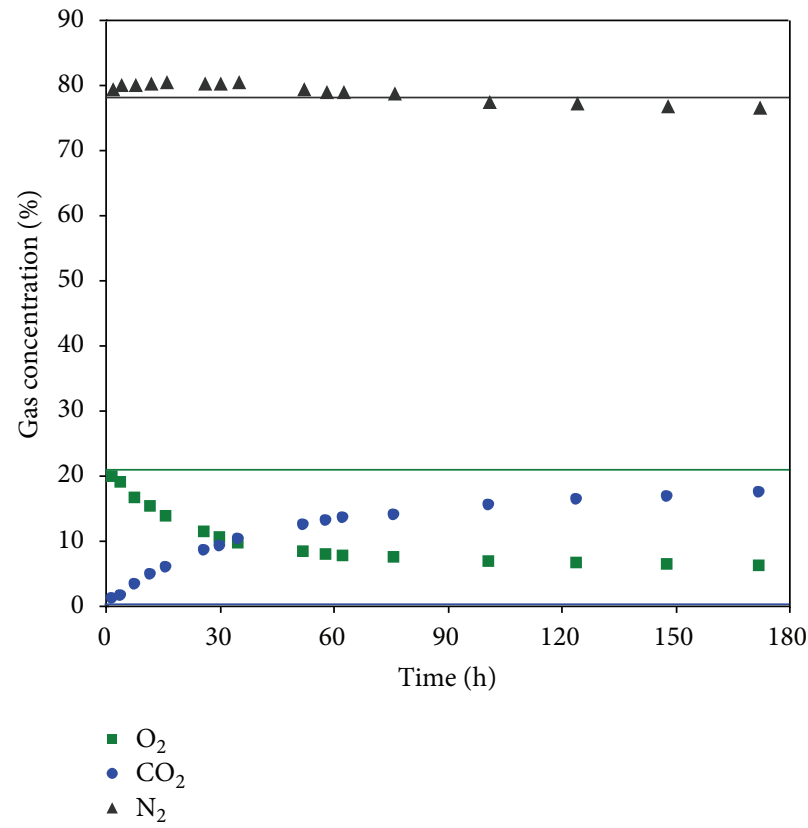

(d)

FIGURE 1: Comparison of the different simulation models used to estimate the gas composition of a strawberry package used by Renault et al. [21]. The microperforated polymeric package with a volume of $1.5 \times 10^{-3} \mathrm{~m}^{3}$ and 8 perforations (diameter: $8.0 \times 10^{-5} \mathrm{~m}$, length: $5.0 \times 10^{-5} \mathrm{~m}$ ) over a surface area of $0.1 \mathrm{~m}^{2}$ contained $0.5 \mathrm{~kg}$ of strawberries at $10^{\circ} \mathrm{C}$. (a) Comprehensive model, (b) simplified diffusion model, (c) Fonseca's empirical model, and (d) Emond's empirical model. Solid lines are the estimated gas compositions.

and simplified diffusion models. The behavior of the solutions was compared between the two models.

\section{Results and Discussion}

3.1. Adequacy Evaluation of the Simulation Models Using the Literature Data. Figures 1-3 compare the results of the package atmosphere simulations to the literature data for several experimental packages. Whereas the comprehensive and simplified diffusion models estimated the package atmosphere well, the two empirical models had poor prediction quality. Fonseca's model was comparable to the comprehensive and simplified diffusion models only for the estimation of the cut onion package with a long perforation (Figure 2(c)).

The data in Table 1 provide evidence for the superiority of the comprehensive and simplified diffusion models to the 


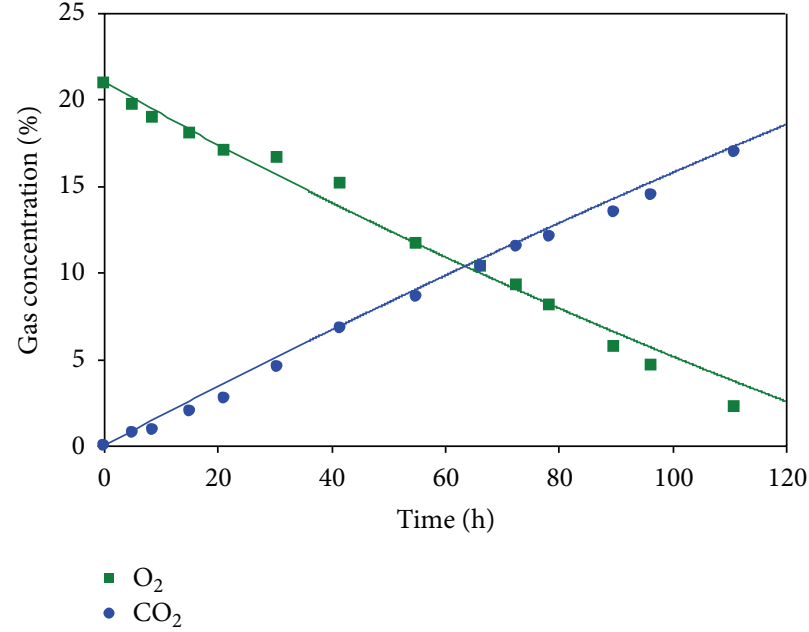

(a)

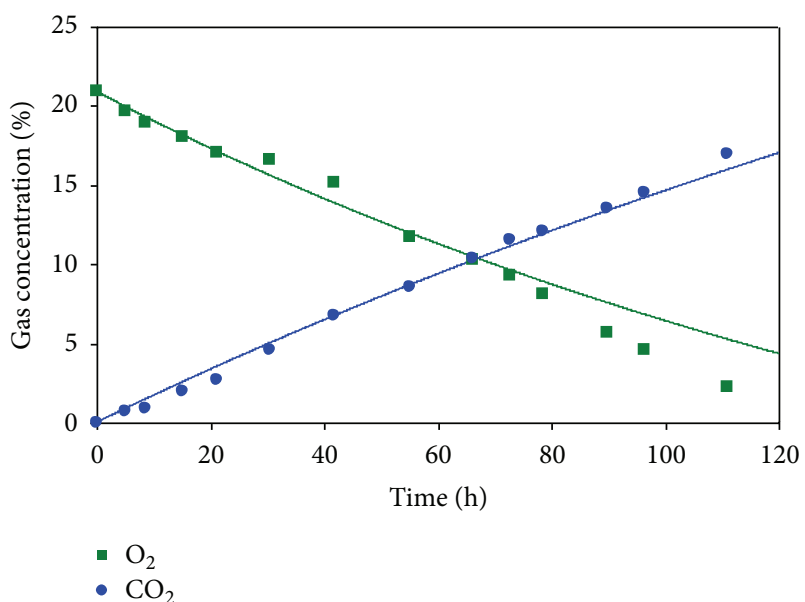

(c)

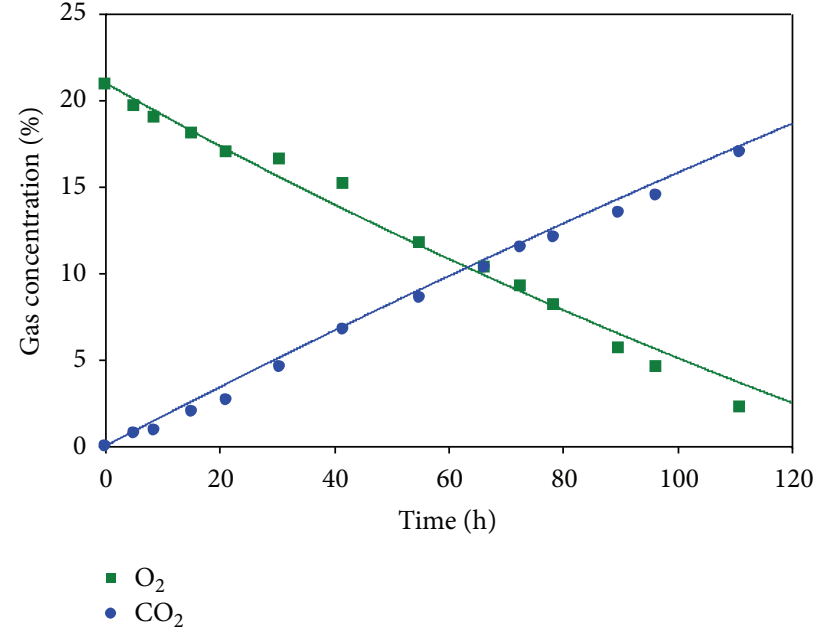

(b)

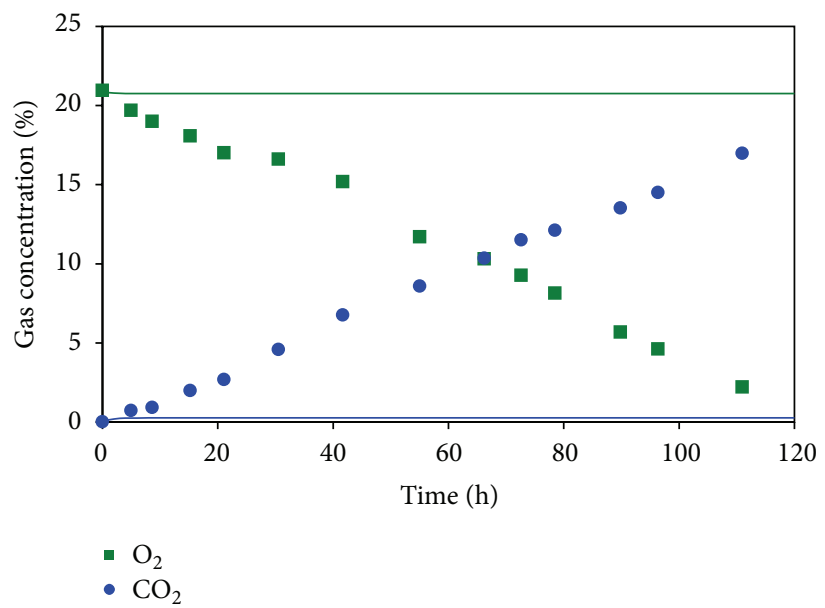

(d)

Figure 2: Comparison of the different simulation models used to estimate the gas composition of a cut onion package used by Lee and Renault [22]. The glass jar package with a free volume of $8.22 \times 10^{-4} \mathrm{~m}^{3}$ and a single perforation (diameter: $3.0 \times 10^{-4} \mathrm{~m}, 1$ length: $2.1 \times 10^{-2} \mathrm{~m}$ ) contained $0.161 \mathrm{~kg}$ of cut onions at $10^{\circ} \mathrm{C}$. (a) Comprehensive model, (b) simplified diffusion model, (c) Fonseca's empirical model, and (d) Emond's empirical model. Solid lines are the estimated gas compositions.

empirical models; these data were from the analysis based on the mean relative deviation modulus, $E$ (11):

$$
E=\frac{100}{N_{e}} \sum_{i=1}^{N_{e}} \frac{\left|C_{\exp }-C_{\text {est }}\right|}{C_{\exp }},
$$

where $N_{e}$ is the experimental data points, $C_{\exp }$ is the experimental gas composition $\left(\mathrm{O}_{2}, \mathrm{CO}_{2}\right.$, and/or $\left.\mathrm{N}_{2}\right)$, and $\mathrm{C}_{\text {est }}$ is the estimated gas composition.

The difference in estimation ability between the comprehensive and simplified diffusion models was minimal, and thus, the two models are comparable.

The empirical models cannot simulate the behavior of the package atmosphere because of their limitations in predicting accurate mass transfer coefficients for different perforation conditions, even though the empirical models can provide the relevant coefficient values and produce an estimation for their range of experimental conditions. There was a better agreement between the estimation of Fonseca's model and the experimental literature data from Figure 2 than between the estimates and the data from Figures 1 and 3 because the perforation conditions were well covered by the experimental perforation dimensions (diameter of $9.0 \times 10^{-3}-1.7 \times 10^{-2} \mathrm{~m}$ and length of $6.0 \times 10^{-3}-3.0 \times 10^{-2} \mathrm{~m}$ ) used to build the model [16]. As observed by Ghosh and Anantheswaran [26], Fonseca's and Emond's empirical models were evaluated to give, for most conditions, much higher mass transfer coefficients than the values purely based on Fick's gas diffusion (specific data omitted here), which led to estimations of less atmosphere modification for the conditions in Figures 1-3 than those with the comprehensive and simplified diffusion models. The empirical mass transfer coefficients $\left(K_{\mathrm{O}_{2}}\right.$ and $K_{\mathrm{CO}_{2}}$ values) implicitly contain the convectional gas transfer in addition to the gas diffusion under the governing 


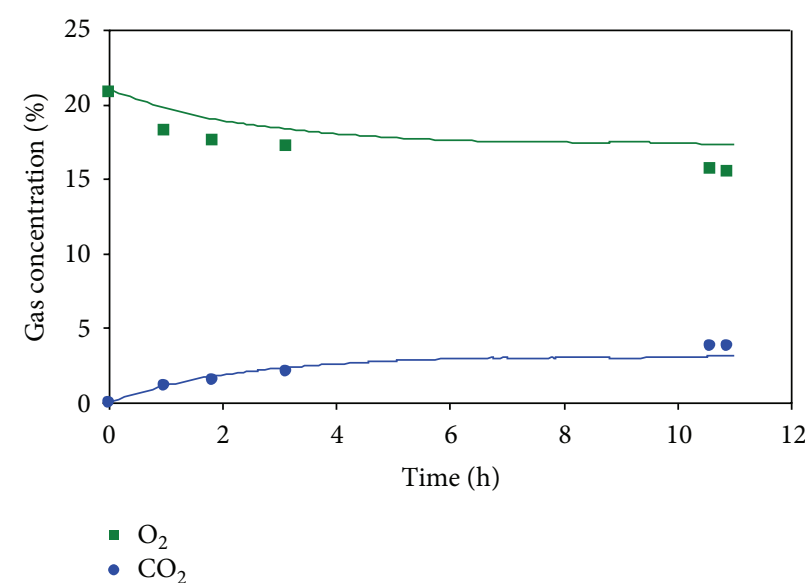

(a)

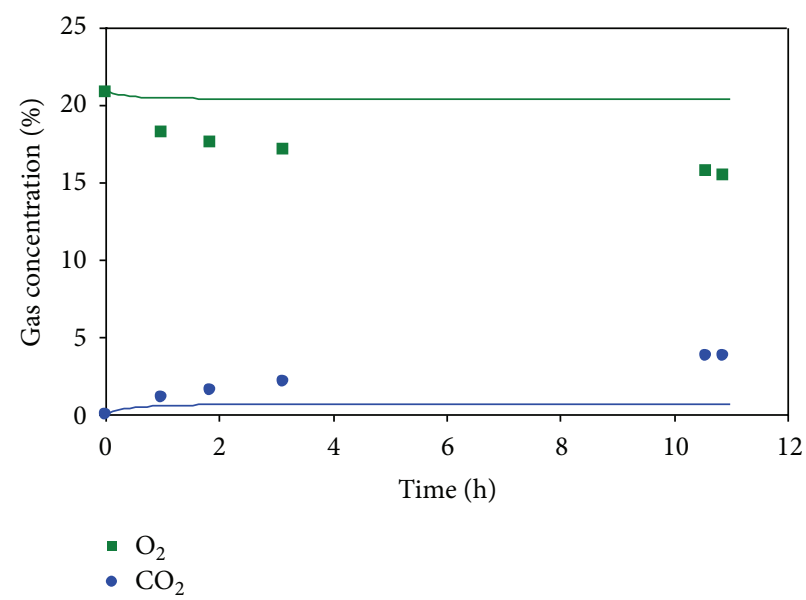

(c)

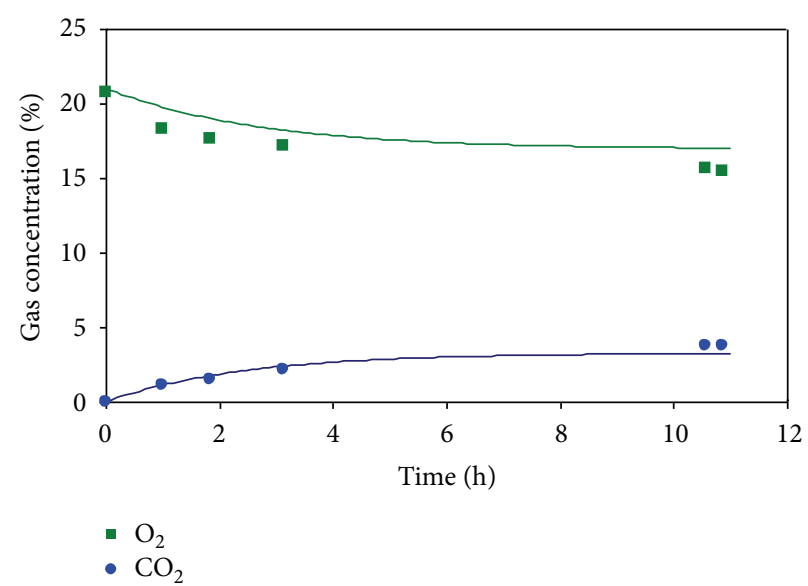

(b)

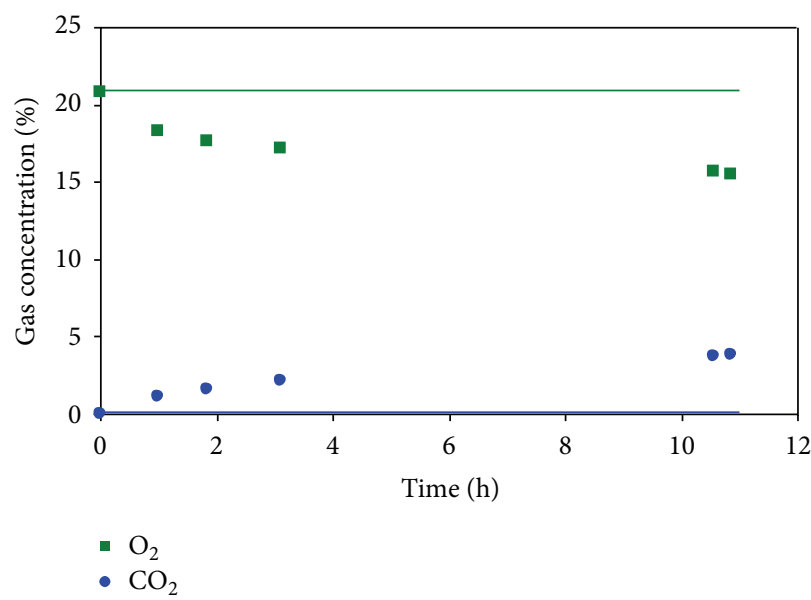

(d)

FIGURE 3: Comparison of the different simulation models used to estimate the gas composition of a peeled garlic package used by Lee et al. [23]. The polymeric package had a volume of $6.1 \times 10^{-4} \mathrm{~m}^{3}$ and 11 perforations (diameter: $4.0 \times 10^{-4} \mathrm{~m}$, length: $3.0 \times 10^{-5} \mathrm{~m}$ ) over a surface area of $0.113 \mathrm{~m}^{2}$ and contained $0.117 \mathrm{~kg}$ of garlic cloves at $20^{\circ} \mathrm{C}$. (a) Comprehensive model, (b) simplified diffusion model, (c) Fonseca’s empirical model, and (d) Emond's empirical model. Solid lines are the estimated gas compositions.

TABLE 1: Mean relative deviation modulus (\%) of the package atmosphere simulated by the different models.

\begin{tabular}{lcccc}
\hline Data set & Comprehensive model & Simplified diffusion model & Fonseca's empirical model & Emond's empirical model \\
\hline Figure 1 & 20.0 & 21.7 & 35.4 & 74.6 \\
Figure 2 & 11.4 & 12.1 & 16.4 & 123.3 \\
Figure 3 & 12.0 & 11.0 & 45.6 & 59.2 \\
\hline
\end{tabular}

experimental conditions. According to Montanez et al. [18], the $K_{\mathrm{O}_{2}}$ and $K_{\mathrm{CO}_{2}}$ values were also influenced by external air turbulence. Therefore, it may be reasoned that the empirical mass transfer coefficients of the perforations are valid only if the perforation dimensions used are accounted for in the original source data and the environmental variables, such as temperature stability and outside air flow, are kept the same as in the conditions used to build the model.

Considering that a wide variety of perforation conditions are being adopted for the packaging of many types of fresh produce, it is difficult to find any empirical gas transfer model that is universally applicable to all packaging situations. In terms of general applicability, the comprehensive and simplified diffusion models are more effective for designing a package with optimal perforation conditions for different commodities.

3.2. Potential of Using the Simplified Diffusion Model for Perforated Packages. Whereas the empirical gas transfer models have the limitation that they can only be used with very similar conditions of their sources, the comprehensive and simplified diffusion models are generally applicable to 


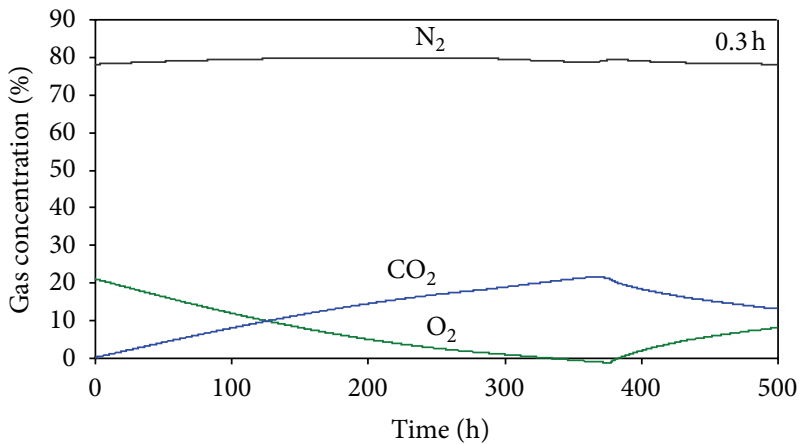

(a)

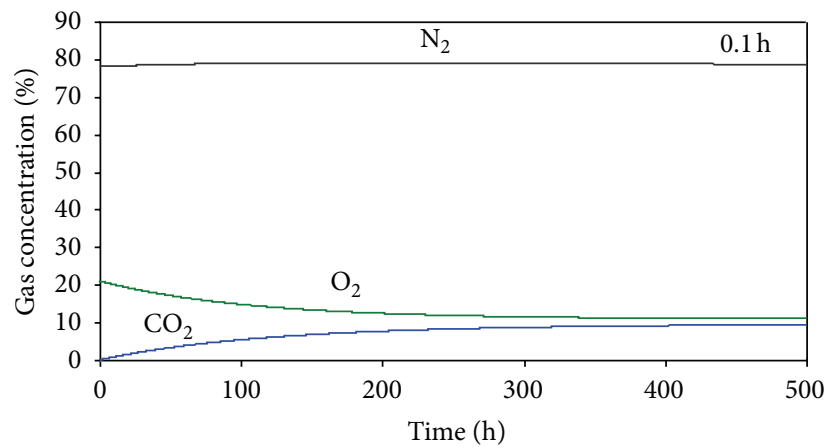

(b)

Figure 4: Numerical solution of (1)-(3) with different time steps. A $2 \mathrm{~mm}$ thick polypropylene package $(0.32 \times 0.23 \times 0.18 \mathrm{~m})$ with a perforation of $3.0 \times 10^{-3} \mathrm{~m}$ in diameter and $2.0 \times 10^{-3} \mathrm{~m}$ in length that contained $0.35 \mathrm{~kg}$ of spinach at $10^{\circ} \mathrm{C}$ was used. The value on the upper right part of each panel is the maximum time step.

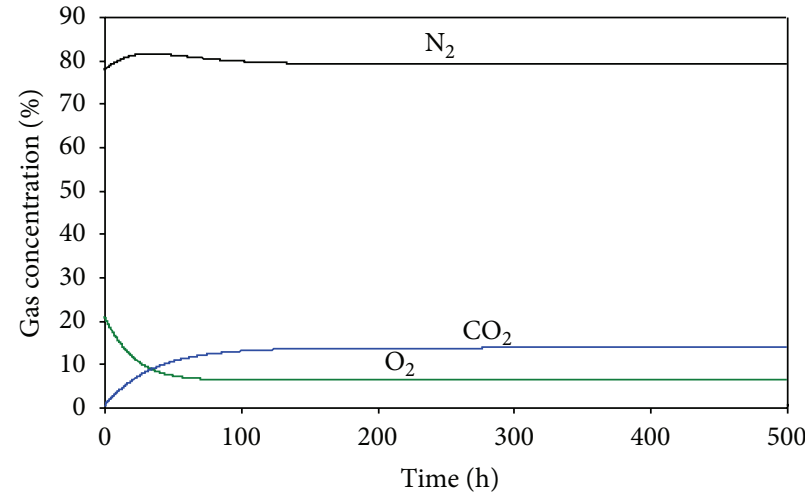

(a)

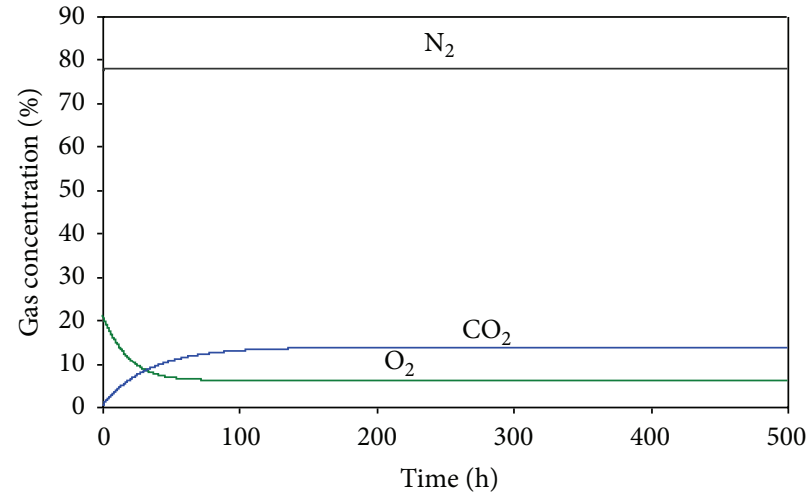

(b)

FIgURE 5: A typical solution set from the comprehensive model (a) and the simplified diffusion model (b) for a perforated model package (perforation with a diameter of $1.0 \times 10^{-2} \mathrm{~m}$ and length of $2.0 \times 10^{-3} \mathrm{~m}$ ) containing $0.9 \mathrm{~kg}$ of king oyster mushrooms at $10^{\circ} \mathrm{C}$.

a variety of conditions, and thus, their properties under different perforation dimensions were investigated for packages of two typical commodities, spinach and king oyster mushrooms.

The comprehensive model of (1)-(3) successfully accounts for the most significant contributions to the mass balance for the produce packaging but often causes an instability problem in the final solutions for certain storage and perforation conditions. This problem is reasoned to come from a disproportionately high value for the convection term among the contributions under certain pressure differential conditions, as reported by Del-Valle et al. $[9,27]$. An example of solution instability arising from the stiffness problem in the comprehensive model can be seen in Figure 4, where the appropriate solution of the differential equations can be achieved only with short time steps in the numerical calculation. Even the stiffness-resistant Gear's method was found to have unstable solutions under certain perforation dimensions and package conditions. Unstable solutions often occurred with perforation conditions of large diameters and short lengths, which are thought to cause a large amount of convection flow due to the small transfer resistance at certain time points. To avoid the instability problem, the convectional terms have often been explicitly or implicitly omitted in the mass balance equations for the perforated MA packaging of fresh produce $[5,13,28]$. The effects of convection transport on improving the theoretical predictions are mostly marginal [17, 20]. Therefore, we investigated the difference between the comprehensive and simplified diffusion models in terms of the estimated package atmosphere for typical perforation dimensional conditions in spinach and king oyster mushroom containers.

For most of the perforation dimensions examined (diameter $3.0 \times 10^{-3}-2.0 \times 10^{-2} \mathrm{~m}$ and length $2.0 \times 10^{-3}-5.0 \times$ $10^{-2} \mathrm{~m}$ for the spinach packages; diameter $5.0 \times 10^{-3}-2.0 \times$ $10^{-2} \mathrm{~m}$ and length $2.0 \times 10^{-3}-1.5 \times 10^{-2} \mathrm{~m}$ for the king oyster mushroom packages), the $\mathrm{O}_{2}$ and $\mathrm{CO}_{2}$ concentrations of the packages in the aerobic atmosphere range were not appreciably different between the two models when the time step size was chosen properly for the comprehensive model (as shown in Figure 5). The simplified diffusion model gave stable solutions regardless of the time step, whereas the maximum time step needs to be adjusted in the comprehensive model. The $\mathrm{N}_{2}$ concentration behaved slightly differently 


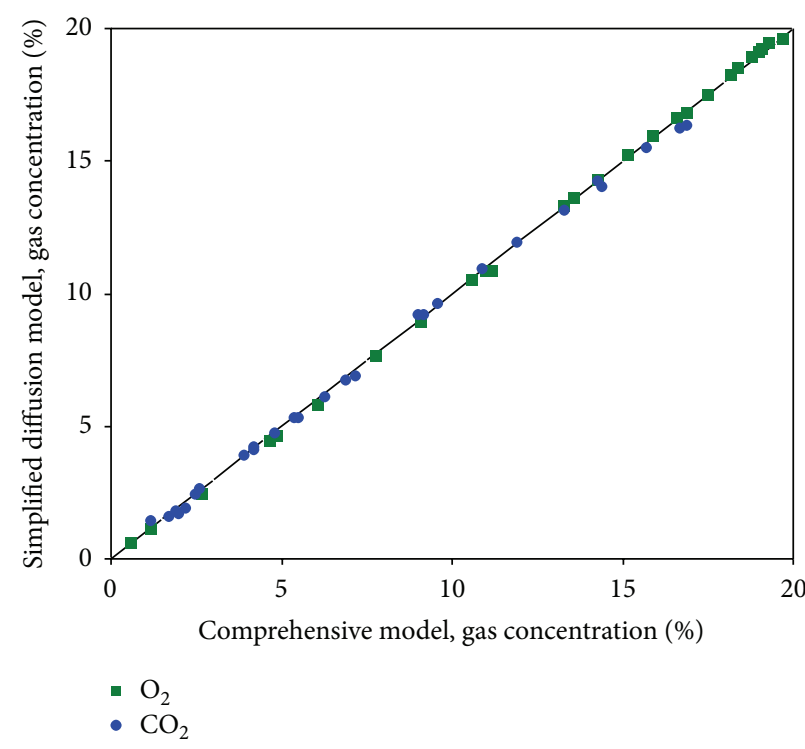

(a)

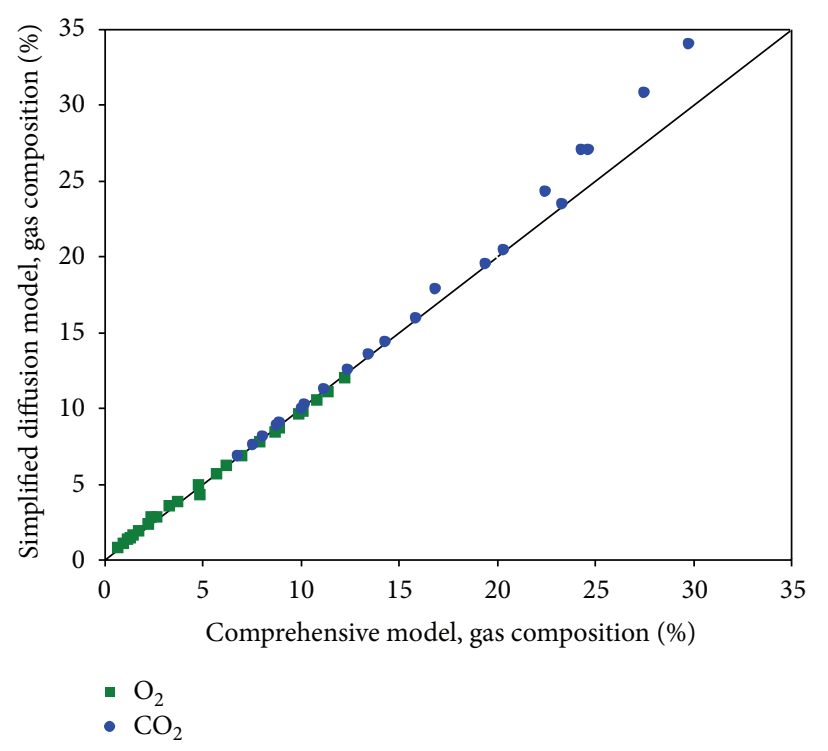

(b)

Figure 6: Comparison of the estimated gas composition between the comprehensive and simplified diffusion models for the perforated model package containing $0.35 \mathrm{~kg}$ spinach (a) or $0.9 \mathrm{~kg}$ king oyster mushrooms (b). The adopted perforations were $3.0 \times 10^{-3}-2.0 \times 10^{-2} \mathrm{~m}$ in diameter and $2.0 \times 10^{-3}-5.0 \times 10^{-2} \mathrm{~m}$ in length for spinach and $5.0 \times 10^{-3}-2.0 \times 10^{-2} \mathrm{~m}$ in diameter and $2.0 \times 10^{-3}-1.5 \times 10^{-2} \mathrm{~m}$ in length for king oyster mushrooms.

between the two models: it was maintained at a constant level of $78 \%$ for the simplified diffusion model, whereas it showed slight fluctuation around $78 \%$ for the comprehensive model. Figure 6 presents the overall agreement between the two models in the estimated equilibrated $\mathrm{O}_{2}$ and $\mathrm{CO}_{2}$ concentrations of the aerobic atmosphere range $\left(\mathrm{O}_{2} \geq 1 \%\right.$, $\left.\mathrm{CO}_{2} \leq 20 \%\right)$. Considering the stability, convenience, and simplicity, the simplified diffusion model without convection terms can be used for most perforated package conditions without a significant sacrifice in the accuracy. The ease of manipulating the equations with appropriate accuracy is the reason why the simplified diffusion model has often been used for simulating perforated fresh produce packaging [12, 13].

Omitting the convection terms from the comprehensive model did not result in significant changes in the package $\mathrm{O}_{2}$ and $\mathrm{CO}_{2}$ concentrations when the $\mathrm{N}_{2}$ concentration was maintained at a relatively constant level of approximately $78 \%$ with an aerobic MA. The vanishing of the convection terms under the constant $\mathrm{N}_{2}$ concentration has been reported by Paul and Clarke [8]. Anaerobic MA conditions with the $\mathrm{CO}_{2}$ concentration increasing above $23 \%$ could not sustain the $\mathrm{N}_{2}$ concentration at $78 \%$ (specific data not shown) and caused the discrepancy in the estimated gas concentrations between the two models (Figure 6(b)). Considering that typical MA packages with perforations have a target MA with a low $\mathrm{O}_{2}$ concentration and high $\mathrm{CO}_{2}$ concentration in the aerobic atmospheric range $[1,3]$, the design of optimal perforated packages may be performed using the assumption of a constant $\mathrm{N}_{2}$ concentration of approximately $78 \%$. Thus, a perforated fresh produce package with the desired MA can be designed using the simplified diffusion model in practical terms.

\section{Conclusions}

By accounting for gas diffusion through package perforation, gas permeation through the polymeric film, and produce respiration, the simplified diffusion model can estimate the atmosphere within the aerobic range inside perforated packages of fresh produce. The omission of the hydraulic convection terms in the mass balance differential equations led to stability in the solutions without affecting the accuracy of the estimated package atmosphere. Published empirical models of the mass transfer coefficients of the perforation are valid only for conditions similar to those used in the measurement setup.

\section{Conflict of Interests}

Mention of trade name in this paper is solely for the purpose of providing specific information and does not imply recommendation or preference by the authors. The authors of this paper do not have any conflict of interests with the trade name.

\section{Acknowledgment}

This study was supported by the Agriculture Research Center Program of the Ministry for Food, Agriculture, Forestry and Fisheries, Republic of Korea (Project no. 710003). 


\section{References}

[1] K. L. Yam and D. S. Lee, "Design of modified atmosphere packaging for fresh produce," in Active Food Packaging, M. L. Rooney, Ed., pp. 55-73, Blackie Academic and Professional, London, UK, 1995.

[2] A. Exama, J. Arul, R. W. Lencki, L. Z. Lee, and C. Toupin, "Suitability of plastic films for modified atmosphere packaging of fruits and vegetables," Journal of Food Science, vol. 58, no. 6, pp. 1365-1370, 1993.

[3] J. D. Mannapperuma and R. P. Singh, "Modeling of gas exchange in polymeric packages of fresh fruits and vegetables," in Minimal Processing of Foods and Process Optimization, R. P. Singh and F. A. R. Oliveira, Eds., pp. 437-458, CRC Press, Boca Raton, Fla, USA, 1994.

[4] F. A. R. Oliveira, S. C. Fonseca, J. C. Oliveira, J. K. Brecht, and K. V. Chau, "Development of perforation-mediated modified atmosphere packaging to preserve fresh fruit and vegetable quality after harvest," Food Science and Technology International, vol. 4, no. 5, pp. 339-352, 1998.

[5] J. González, A. Ferrer, R. Oria, and M. L. Salvador, "Determination of $\mathrm{O}_{2}$ and $\mathrm{CO}_{2}$ transmission rates through microperforated films for modified atmosphere packaging of fresh fruits and vegetables," Journal of Food Engineering, vol. 86, no. 2, pp. 194201, 2008.

[6] R. Rodriguez-Aguilera and J. C. Oliveira, "Review of design engineering methods and applications of active and modified atmosphere packaging systems," Food Engineering Reviews, vol. 1, no. 1, pp. 66-83, 2009.

[7] J. González-Buesa, A. Ferrer-Mairal, R. Oria, and M. L. Salvador, "A mathematical model for packaging with microperforated films of fresh-cut fruits and vegetables," Journal of Food Engineering, vol. 95, no. 1, pp. 158-165, 2009.

[8] D. R. Paul and R. Clarke, "Modeling of modified atmosphere packaging based on designs with a membrane and perforations," Journal of Membrane Science, vol. 208, no. 1-2, pp. 269-283, 2002.

[9] V. Del-Valle, E. Almenar, J. M. Lagarón, R. Catalá, and R. Gavara, "Modelling permeation through porous polymeric films for modified atmosphere packaging," Food Additives and Contaminants, vol. 20, no. 2, pp. 170-179, 2003.

[10] C. Ratti, H. R. Rabie, and G. S. V. Raghavan, "Modelling modified atmosphere storage of fresh cauliflower using diffusion channels," Journal of Agricultural Engineering Research, vol. 69, no. 4, pp. 343-350, 1998.

[11] Y. H. Jo, N. Y. Kim, D. S. An, H. J. Lee, and D. S. Lee, "Modified atmosphere container equipped with gas diffusion tube automatically controlled in response to real-time gas concentration," Biosystems Engineering, vol. 115, no. 3, pp. 250259, 2013.

[12] L. Zanderighi, "How to design perforated polymeric films for modified atmosphere packs (MAP)," Packaging Technology and Science, vol. 14, no. 6, pp. 253-266, 2001.

[13] S. K. Pandey and T. K. Goswami, "Modelling perforated mediated modified atmospheric packaging of capsicum," International Journal of Food Science and Technology, vol. 47, no. 3, pp. 556-563, 2012.

[14] O. J. Stewart, G. S. V. Raghavan, K. D. Golden, and Y. Gariépy, "MA storage of Cavendish bananas using silicone membrane and diffusion channel systems," Postharvest Biology and Technology, vol. 35, no. 3, pp. 309-317, 2005.
[15] J. P. Emond, F. Castaigne, C. J. Toupin, and D. Desilets, "Mathematical modeling of gas exchange in modified atmosphere packaging," Transactions of the American Society of Agricultural Engineers, vol. 34, no. 1, pp. 239-245, 1991.

[16] S. C. Fonseca, F. A. R. Oliveira, I. B. M. Lino, J. K. Brecht, and K. V. Chau, "Modelling $\mathrm{O}_{2}$ and $\mathrm{CO}_{2}$ exchange for development of perforation-mediated modified atmosphere packaging," Journal of Food Engineering, vol. 43, no. 1, pp. 9-15, 2000.

[17] T. J. Rennie and S. Tavoularis, "Perforation-mediated modified atmosphere packaging - part II: implementation and numerical solution of a mathematical model," Postharvest Biology and Technology, vol. 51, no. 1, pp. 10-20, 2009.

[18] J. C. Montanez, F. A. S. Rodríguez, P. V. Mahajan, and J. M. Frías, "Modelling the gas exchange rate in perforation-mediated modified atmosphere packaging: effect of the external air movement and tube dimensions," Journal of Food Engineering, vol. 97, no. 1, pp. 79-86, 2010.

[19] N. Techavises and Y. Hikida, "Development of a mathematical model for simulating gas and water vapor exchanges in modified atmosphere packaging with macroscopic perforations," Journal of Food Engineering, vol. 85, no. 1, pp. 94-104, 2008.

[20] G. Xanthopoulos, E. D. Koronaki, and A. G. Boudouvis, "Mass transport analysis in perforation-mediated modified atmosphere packaging of strawberries," Journal of Food Engineering, vol. 111, no. 2, pp. 326-335, 2012.

[21] P. Renault, L. Houal, G. U. Y. Jacquemin, and Y. Chambroy, "Gas exchange in modified atmosphere packaging. 2: experimental results with strawberries," International Journal of Food Science \& Technology, vol. 29, no. 4, pp. 379-394, 1994.

[22] D. S. Lee and P. Renault, "Using pinholes as tools to attain optimum modified atmospheres in packages of fresh produce," Packaging Technology and Science, vol. 11, no. 3, pp. 119-130, 1998.

[23] D. S. Lee, J. S. Kang, and P. Renault, "Dynamics of internal atmosphere and humidity in perforated packages of peeled garlic cloves," International Journal of Food Science and Technology, vol. 35, no. 5, pp. 455-464, 2000.

[24] D. S. Lee, P. E. Haggar, J. Lee, and K. L. Yam, "Model for fresh produce respiration in modified atmospheres based on principles of enzyme kinetics," Journal of Food Science, vol. 56, no. 6, pp. 1580-1585, 1991.

[25] S. C. Fonseca, F. A. R. Oliveira, and J. K. Brecht, "Modelling respiration rate of fresh fruits and vegetables for modified atmosphere packages: a review," Journal of Food Engineering, vol. 52, no. 2, pp. 99-119, 2002.

[26] V. Ghosh and R. C. Anantheswaran, "Oxygen transmission rate through micro-perforated films: measurement and model comparison," Journal of Food Process Engineering, vol. 24, no. 2, pp. 113-133, 2001.

[27] R. W. Hornbeck, Numerical Methods, Prentice-Hall, Englewood Cliffs, NJ, USA, 1975.

[28] S. Fishman, V. Rodov, J. Peretz, and S. Ben-Yehoshua, "Model for gas exchange dynamics in modified-atmosphere packages of fruits and vegetables," Journal of Food Science, vol. 60, no. 5, pp. 1078-1987, 1995. 


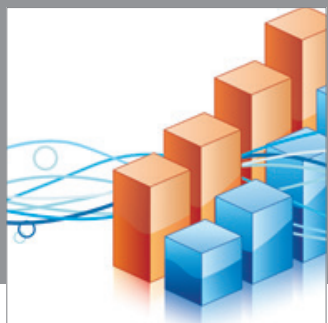

Advances in

Operations Research

mansans

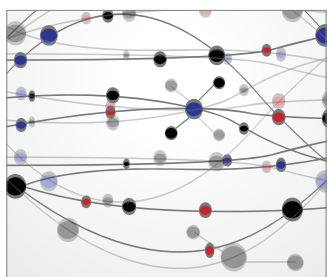

The Scientific World Journal
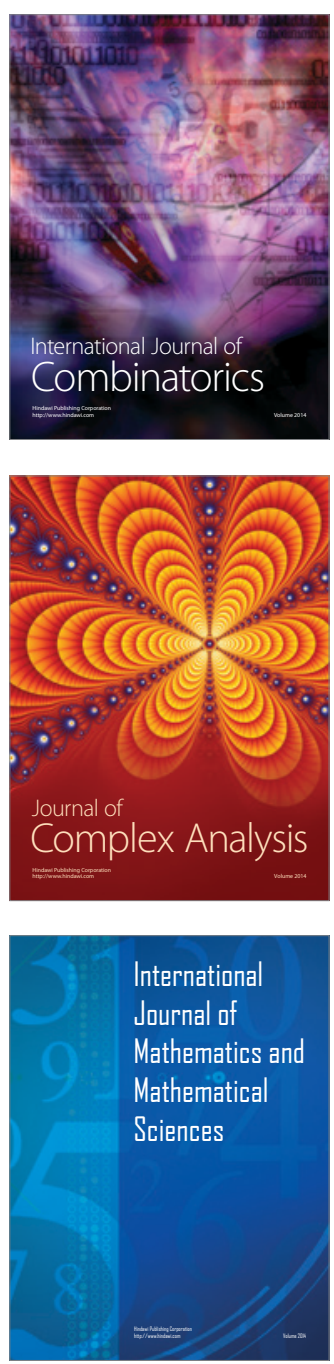
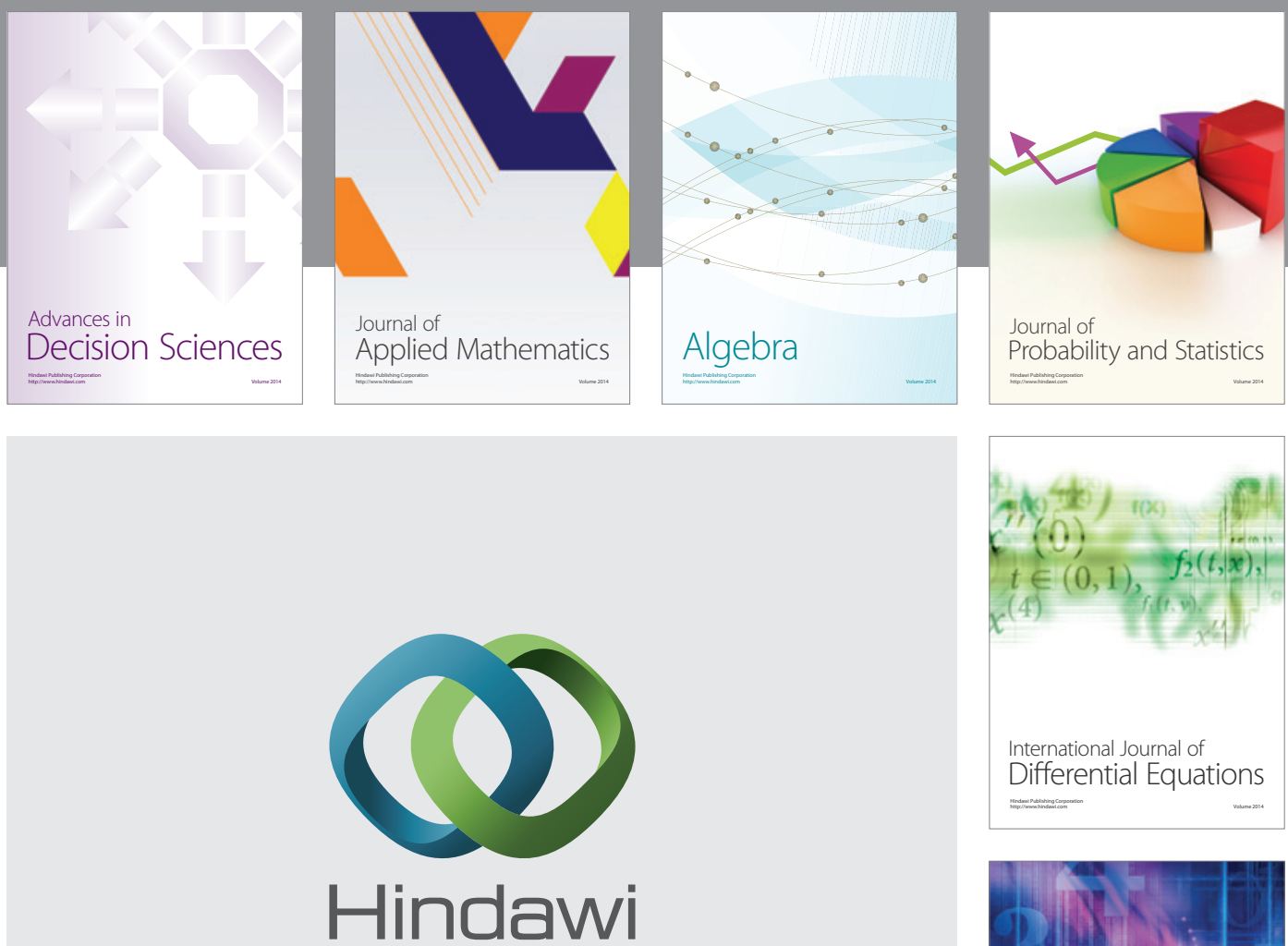

Submit your manuscripts at http://www.hindawi.com
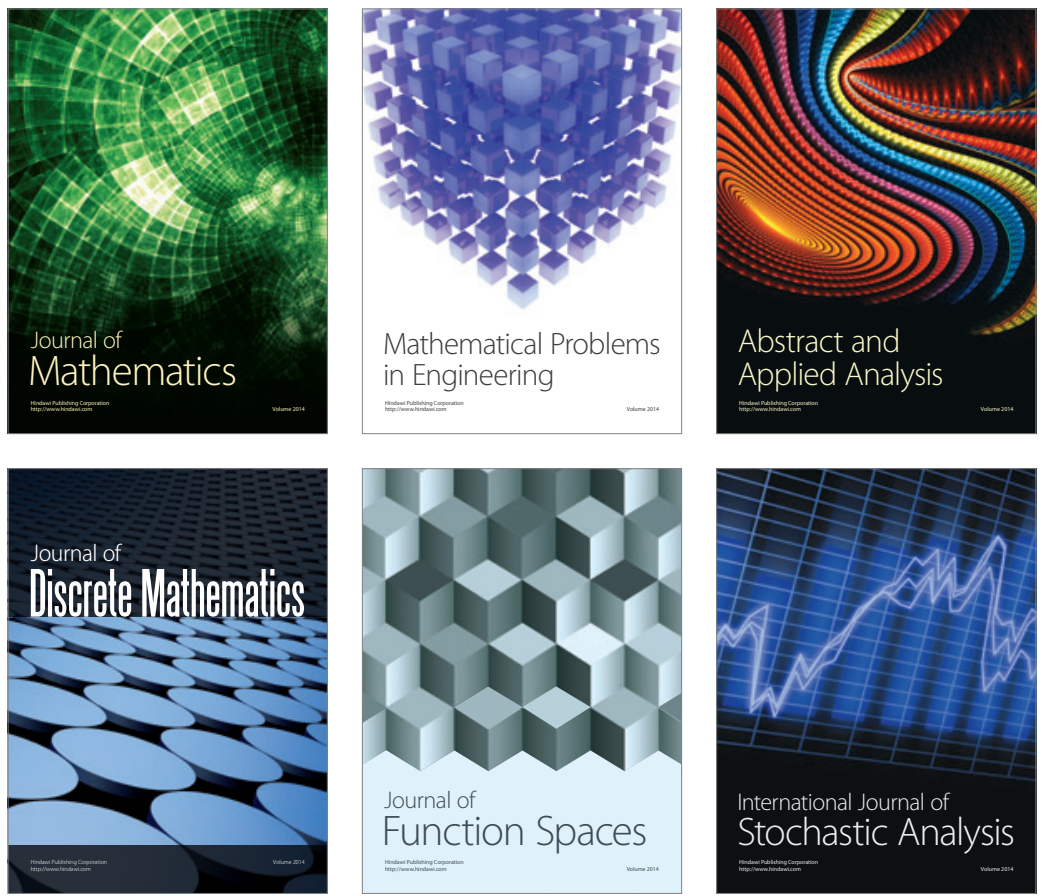

Journal of

Function Spaces

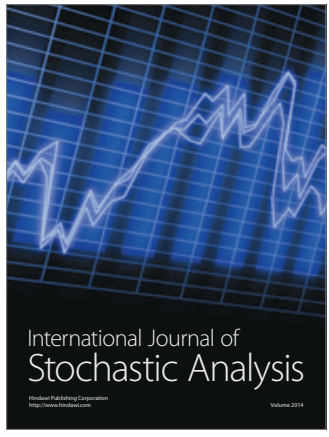

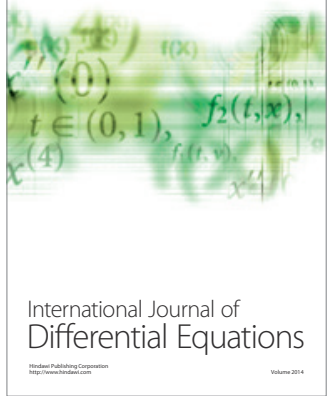
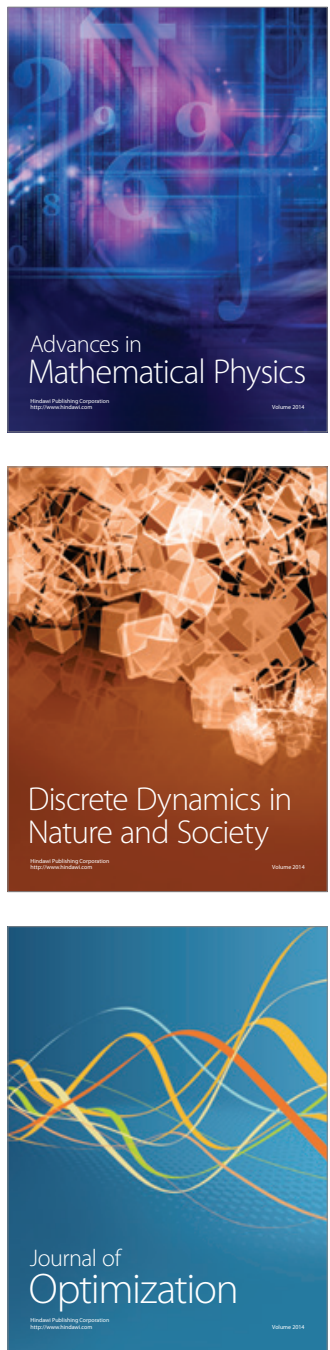